\title{
ENDOGENEIDADE DO SETOR FINANCEIRO \\ E CRESCIMENTO ECONÔMICO \\ UMA ANÁLISE EMPÍRICA PARA A ECONOMIA \\ BRASILEIRA (1980-2003)*
}

\author{
Eliane Cristina de Araújo ${ }^{* *}$
}

Joilson Dias ${ }^{* * *}$

\begin{abstract}
RESUMO O presente trabalho apresenta um modelo teórico de quatro setores que endogeiniza o setor financeiro da economia submetendo-o às decisões das famílias e do governo. Como resultado, temos que as variáveis monetárias taxa de juros, política de reservas bancárias e imposto inflacionário influenciam o crescimento econômico. Essa relação foi estimada para a economia brasileira a partir da metodologia de Vetores Auto-Regressivos (VAR) e dos testes de exogeneidade fraca e forte. Esses testes revelaram que a taxa de juros e o imposto inflacionário possuem uma relação endógena com a taxa de crescimento da economia e afetam somente a sua variabilidade. No entanto, a política de reservas bancárias apresentou-se como exógena, tendo efeitos permanentes sobre essa mesma taxa. Em resumo, a política de reservas bancárias determina o montante de empréstimos da economia, que conseqüentemente influencia o crescimento econômico. Nossas estimações indicaram que a elevação em 10 pontos percentuais na alíquota de reservas bancárias reduz a taxa de crescimento da economia em até $1,2 \%$.
\end{abstract}

Palavras-chave: crescimento econômico; setor financeiro; exogeneidade Código JEL: C32, E44

* Artigo recebido em 3 de fevereiro de 2005 e aprovado em $1^{\circ}$ de setembro de 2006.

** Doutoranda em Economia, Universidade Federal do Rio de Janeiro, e-mail: elianedearaujo@yahoo. com.br

*** Professor titular, Departamento de Economia, Universidade Estadual de Maringá, e-mail: jdias@ uem.br 


\title{
ENDOGENEITY OF FINANCIAL SECTOR AND ECONOMIC GROWTH:
}

\section{AN EMPIRICAL ANALYZE OF THE BRASILIAN ECONOMY}

\begin{abstract}
The objective of this paper is to build a four sector model that make the financial sector endogenous and under the influence of families and government policies. As a result, the long run economic growth is influenced by monetary variables like the size of bank reserves, interest rates and inflationary tax. This model was empirically estimated through Auto-regressive Vector (VAR) and submitted to exogeneity tests. The results were that interest rate and inflationary tax are endogenously related to economic growth and affect only its variability. However, the bank reserve policy is exogenous to this variable and showed to have permanent effect on it, more specifically, in sum, the reserve bank policy set the amount of loan in the economy and it influences economic growth. Our estimation indicates that the rise of the bank reserve in 10 points might reduce the economic growth rate as much as $1.2 \%$.
\end{abstract}

Key words: economic growth; financial sector; exogeneity 


\section{INTRODUÇÃO}

Nas teorias de crescimento econômico, a importância do setor financeiro tem recebido destaque, tornando-se objeto de estudo mais intenso com os trabalhos seminais de Goldsmith (1969) e Shaw (1973), que encontraram evidência empírica acerca da relação positiva entre desenvolvimento financeiro e crescimento econômico.

A partir da década de 1990, inicia-se uma profunda investigação a respeito da importância do setor financeiro para a economia no longo prazo. Sendo assim, vários trabalhos foram desenvolvidos buscando explicar a relevância do sistema financeiro para o crescimento econômico, entre os quais ressaltam-se Smith (1991), Pagano (1993), Becsi e Wang (1997) e Bebczuk (2001). A importância dessa literatura reside no fato de que o sistema financeiro torna a alocação dos recursos monetários mais eficiente, o que conduz a uma maior captação de poupança e, em conseqüência, à elevação no volume de recursos a serem emprestados. Tais recursos, quando destinados a maiores investimentos em capital físico e humano, geram maior crescimento econômico.

Esses insights foram formalizados e estendidos por meio de discussões sobre a endogeneidade ou exogeneidade da relação entre intermediação financeira e crescimento econômico. A partir de então, vários testes foram realizados para constatar se o sistema financeiro era endógeno ou exógeno. O trabalho de Levine et al. (2000) revisa esses aspectos da literatura e utiliza os procedimentos de variáveis instrumentais e dados de painéis dinâmicos para constatar empiricamente a relação endógena entre o setor financeiro e o crescimento econômico. A partir dessa comprovação, a relação entre as duas variáveis passaria a depender de políticas econômicas exógenas.

Contudo, faltava um modelo teórico que captasse essa relação existente entre desenvolvimento financeiro e crescimento econômico e que demonstrasse a endogeneidade do setor financeiro. Buscando preencher essa lacuna, alguns autores iniciaram a construção de modelos de crescimento econômico endogeneizando o sistema financeiro, como Fuente e Marin (1996) e Basu (2001).

As evidências empíricas brasileiras referentes à relação entre desenvolvimento do sistema financeiro e crescimento econômico podem ser encontradas nos estudos de Arraes e Teles (2000), Monte e Távora Júnior (2000), 
Matos (2002) e Marques e Porto (2004). Os resultados obtidos com esses trabalhos revelam, em geral, a existência de uma relação unidirecional positiva entre desenvolvimento financeiro e crescimento econômico, ou seja, os dados dão suporte à hipótese de que o sistema financeiro é indutor do crescimento da economia brasileira. No entanto, esses trabalhos utilizam medidas diversas de agregados monetários como representantes do desenvolvimento do sistema financeiro, sem todavia observarem que elas estão muito mais próximas de representarem políticas econômicas do que o sistema financeiro.

Dentro desse contexto, o presente artigo apresenta um modelo teórico que estabelece a endogeneidade do sistema financeiro, o que é testado empiricamente para a economia brasileira. $\mathrm{O}$ modelo proposto se coloca como uma extensão do modelo de Basu (2001), contribuindo com a inclusão do governo e com políticas econômicas para entender as mudanças na taxa de crescimento do produto. No modelo apresentado, as famílias transferem o consumo de um período para outro efetuando depósitos nos bancos comerciais, que serão remunerados por uma taxa de juros. Os bancos, por sua vez, manterão parte desses depósitos em caixa sob a forma de recolhimento compulsório, que estará sujeito ao imposto inflacionário, e a outra parte emprestarão às firmas a uma determinada taxa de juros. As firmas converterão esses empréstimos em estoque de capital utilizando-o no processo de produção. O governo atuará investindo em infra-estrutura, o que também servirá de insumo de produção para as firmas, representando parte de seu estoque de capital. Por fim, é a decisão das famílias de quanto manter de depósito nos bancos comerciais e a política de reservas bancárias que levarão à equação fundamental do modelo. Dadas as relações propostas entre os agentes, o modelo estabelece a endogeneidade do setor financeiro, tendo em vista que este é o intermediário entre a poupança das famílias e o investimento das firmas.

A análise empírica terá como enfoque o impacto da taxa de juros, imposto inflacionário e reservas bancárias sobre a taxa de crescimento da economia brasileira, entre os anos 1980 e 2003, verificando a endogeneidade ou exogeneidade dessas variáveis no processo. Para atingir o objetivo proposto, o artigo encontra-se estruturado da seguinte forma: a seção 1 traz um modelo de crescimento endógeno que apresenta a relação matemática entre o setor financeiro e a taxa de crescimento econômico. Na seção 2, utilizare- 
mos a metodologia de séries temporais, precisamente os modelos de Vetores Auto-Regressivos (VAR), para estimar a relação empírica entre essas variáveis. Por fim, a última seção está reservada às conclusões desta pesquisa.

\section{O MODELO DE CRESCIMENTO ECONÔMICO}

O modelo aqui proposto relaciona a decisão das famílias de poupar, o papel do setor bancário na intermediação financeira, a atuação do governo na captação de recursos e a realização de investimentos em infra-estrutura e, por fim, a participação das firmas que demandam empréstimos para a formação de capital fixo. A inter-relação entre esses setores foi desenvolvida nos trabalhos de Basu (2001), Haslag (1998) e Chari, Jones e Manuelli (1995), os quais pretendemos utilizar como base.

Inicialmente, o modelo considera quatro agentes tomadores de decisão que interagem na economia: bancos, famílias, firmas e governo. As firmas produzem utilizando capital $\left(K_{t}\right)$, trabalho $\left(N_{t}\right)$ e gastos em infra-estrutura governamental $\left(G_{t}\right)$ como insumos de produção. Dessa forma, a função de produção é dada por:

$$
Y_{t}=f\left(K_{t}, N_{t}, G_{t}\right)
$$

Assume-se também que não há crescimento da população e que o trabalho é inelasticamente ofertado em um "único nível". Essas hipóteses têm como objetivo facilitar a exposição e não são restritivas ao resultado esperado.

A introdução de $(G)$ na função de produção segue a aproximação de Barro (1990), que considera essa variável como um insumo não rival e não exclusivo no processo de produção. Cada firma toma o nível inicial de $(G)$ como dado enquanto planeja o seu processo de acumulação de capital.

Neste sentido, as firmas se deparam com a restrição de que todo investimento hoje depende dos novos empréstimos tomados junto aos bancos comerciais.

\subsection{Problema de maximização das firmas}

Formalmente, as firmas se deparam com o problema de maximizar o valor presente do estoque composto de seu capital $(K)$ : 


$$
\max \int_{0}^{\infty} e^{-r t}\left[P_{t} y_{t}+P_{t} \dot{L}_{t}-r P_{t} L t-P_{t} \delta \dot{K}_{t}-W_{t}\right]
$$

sujeito a $P_{t} \dot{\mathrm{K}}_{t} \leq P_{t} \dot{L}_{t}$

$$
P_{t} \dot{K}_{t}-P_{t} \dot{L}_{t} \leq 0
$$

em que $L_{t}$ são os empréstimos bancários recebidos no período $t$, $Y_{t}$ é o nível de produto em $t, K_{t}$ é o capital usado no processo de produção em $t, P_{t}$ é o nível de preços nominal no período $t, r_{t}$ é a taxa de juros real dos empréstimos em $t, W_{t}$ é o salário nominal no período $t$, e $\delta$ é a taxa de depreciação do estoque de capital no tempo. Todas as variáveis apresentadas na forma $\dot{X}_{t}$ representam $\partial X$, indicando a variação de $X$ em relação ao tempo. As firmas $\overline{\partial t}$

se apropriam de todo o estoque de capital e se deparam com um problema dinâmico, visto que recebem novos empréstimos $\left(\dot{L}_{t}\right)$ dos bancos, os quais restringem seus gastos com novos capitais $\left(\dot{K}_{t}\right)$, o que é mostrado na restrição orçamentária com que a firma se depara (equação 3 ).

Dividindo-se a equação (2) por $P_{t}$ tem-se:

$$
\max \int_{0}^{\infty} e^{-r t}\left(y_{t}+\dot{l}_{t}-r_{t} l_{t}-\delta \dot{k}_{t}-w_{t}\right)
$$

Neste caso, todas as variáveis estão sendo escritas em valores reais. Desenvolvendo o modelo, inicialmente apresentado por Basu (2001), e considerando que $y_{t}=f\left(k_{t}, g_{t}\right)$, é possível reescrever (2) como:

$$
\phi=f\left(k_{t}, g_{t}\right)+\dot{l}_{t}-r l_{t}-\delta \dot{k}_{t}-w_{t}
$$

onde $\phi$ representa a função lucro da firma.

Através das condições de primeira ordem, podemos encontrar as equações (7) e (9):

$$
\frac{\partial \phi}{\partial \dot{\mathrm{k}}}=f_{k}\left(k_{t}, g_{t}\right) \dot{k}-1=0 \quad \Rightarrow \dot{k}=\frac{1}{f_{k}\left(k_{t}, g_{t}\right)}
$$


Pela equação (7), é possível verificar que a variação no estoque de capital é inversamente proporcional à produtividade marginal do capital. Portanto, quanto mais produtivo for o capital, menor será sua acumulação no tempo.

$$
\begin{aligned}
& \text { onde } f_{k} \text { representa: } f_{k}=\frac{\partial(k, g)}{\partial k} \\
& \frac{\partial \phi}{\partial \dot{l}}=1-r_{t} \dot{l}=0 \quad \Rightarrow i=\frac{1}{r_{t}}
\end{aligned}
$$

Já a equação (9) revela que a variação dos empréstimos tomados pelas firmas no tempo está inversamente relacionada à taxa de juros. Assim, quanto maior for a taxa de juros real, menor será o volume de empréstimos que as firmas tomarão junto aos bancos.

Portanto, a realização de novos empréstimos pelas firmas determinará a sua aquisição de novos capitais, sendo que a variação do volume de empréstimos tomados pelas firmas no tempo será igual à variação do estoque de capital no tempo, ou seja, $\dot{k}=\dot{i}$, o que torna possível escrever:

$$
\frac{1}{r_{t}}=\frac{1}{f_{k}\left(k_{t}, g_{t}\right)}
$$

Assim, podemos encontrar a taxa de juros como uma solução de escolha ótima das firmas com relação aos empréstimos contraídos:

$$
r_{t}=f_{k}(k, g)
$$

Como a taxa de juros real é igual a $i_{t}^{L}-\frac{\dot{P}_{1}}{P_{t}}$, ou seja, a taxa nominal de juros menos a variação nos preços, temos que:

$$
\left(\mathrm{i}_{t}^{L}-\frac{\dot{P}_{t}}{P_{t}}\right)=f_{k}
$$

Assumindo que a restrição financeira é imposta, o problema de maximização das firmas se reduz a um problema de análise estática comparativa, e a taxa de desconto envolvida se torna irrelevante. Sendo assim, a condição de equilíbrio para as firmas é que a taxa de juros real seja igual ao produto marginal do capital $\left(f_{k}\right)$ (Basu, 2001). 


\subsection{0 problema de maximização dos bancos}

Existe no modelo um sistema bancário competitivo que recebe o depósito das famílias e concede empréstimos às firmas. Assumimos que esse sistema de intermediação possui custos para a atividade econômica. Um requerimento legal impõe um limite sobre a fração dos depósitos nominais mantidos na forma de moeda. Exceto por meio desse requerimento estatutário, não existe outra razão para se manter moeda no modelo.

De acordo com Basu (2001), a oferta de moeda nominal é dada por: $M_{t}=$ $\varepsilon D_{t}$, em que $D_{t}$ representa os depósitos das famílias nos bancos no período te $\varepsilon_{t}$ representa as reservas bancárias obrigatórias no período $t$.

A função de lucro dos bancos é representada da seguinte forma:

$$
\pi b=\left(1+i_{t}^{L}\right) L t+M_{t}-\left(1+i_{t}^{D}\right) D_{t}=0
$$

em que $\pi b$ representa o lucro dos bancos, $M_{t}$ representa a quantidade de moeda nominal no período $t, L_{t}$ representa os empréstimos nominais no período $t, i_{t}^{D}$ e $i_{t}^{L}$ são as taxas de juros que remuneram os depósitos e empréstimos no período $t$, respectivamente.

Para facilitar, podemos escrever $1+i_{t}^{D}=r^{D}$ e $1+i_{t}^{L}=r^{L}$, o que nos permite apresentar a equação (12) como:

$$
\pi b=\left(r^{L}\right) L_{t}+\varepsilon D_{t}-\left(r^{D}\right) D_{t}
$$

Sendo:

$$
\begin{aligned}
& L t=D_{t}-M_{t} \\
& L t=D_{t}-\varepsilon_{t} D_{t}
\end{aligned}
$$

Substituindo a relação de (14) em (13), podemos encontrar a seguinte representação para a função lucro dos bancos:

$$
\pi b=r^{L}\left(D_{t}-\varepsilon D_{t}\right)+\varepsilon D_{t}-\varepsilon r^{D}-r^{D} D_{t}
$$

A condição de entrada livre no setor bancário implica lucro econômico zero para os bancos, o que possibilita igualar a equação (15) a zero. Além disso, dividindo por $D$, temos: 


$$
\begin{aligned}
& \pi b=r^{L}-r^{L} \varepsilon+\varepsilon-r^{D}=0 \\
& r^{L}(1-\varepsilon)+\varepsilon=r^{D}
\end{aligned}
$$

A solução pressupõe encontrar a taxa de juros de empréstimos que maximiza o lucro dos bancos.

$$
\begin{aligned}
& r^{L}=\frac{r^{D}}{(1-\varepsilon)}-\frac{\varepsilon}{(1-\varepsilon)} \\
& \left(1+i_{t}^{L}\right)=\frac{\left(1+i_{t}^{D}\right)}{(1-\varepsilon)}-\frac{\varepsilon}{(1-\varepsilon)} \\
& i^{L}=\frac{1}{(1-\varepsilon)}+\frac{i^{D}}{1-\varepsilon}-\frac{\varepsilon}{1-\varepsilon}-\frac{1-\varepsilon}{1-\varepsilon} \\
& i^{L}=\frac{i^{D}}{(1-\varepsilon)}
\end{aligned}
$$

A equação (16) representa a condição de equilíbrio para o setor bancário, na qual a política de depósitos compulsórios do governo leva a um diferencial entre a taxa de juros que incide sobre os empréstimos e a que remunera os depósitos. Assim, quanto maior for a alíquota de recolhimento compulsório, maior será a taxa de juros que remunera os depósitos e a que incide sobre os empréstimos.

A função de demanda por moeda assume a seguinte forma:

$$
M_{t}=\varepsilon_{t} d_{t} P_{t}
$$

na qual $D t$ são os depósitos reais no período $t$.

Nessa economia, consideramos ainda que a oferta de moeda efetuada pelo Banco Central é $\left(\overline{M_{t}}\right)$, assumindo os depósitos das famílias $\left(D_{t}\right)$ e as taxas de juros $\left(i_{t}^{L}\right)$ e $\left(i_{t}^{D}\right)$ como dadas. Desta forma, o Banco Central escolhe a trajetória da oferta de moeda no tempo de tal modo que, em cada período, a oferta seja igual à demanda por moeda, ou seja:

$$
\bar{M}_{t}=\varepsilon_{t} d_{t} P_{t}
$$


Portanto, a equação (18) representa a condição de equilíbrio do mercado monetário.

\subsection{0 governo}

Em conformidade com a estrutura do modelo aqui delineada, a política monetária adotada pelo governo tem como objetivo manter a quantidade real de moeda da economia constante. Desta forma:

$$
\begin{aligned}
& \frac{\partial(M / P)}{\partial t}=\frac{\frac{\partial(M)}{\partial t} P-M \frac{\partial(P)}{\partial t}}{P^{2}}=0 \\
& \frac{\dot{M}}{P}-\frac{\dot{M P}}{P^{2}}=0 \\
& \frac{\dot{M}}{P}=\frac{M}{P}-\frac{\dot{P}}{P}
\end{aligned}
$$

Então:

$$
\frac{\dot{M}}{P}=\pi \frac{M}{P} \quad \text { em que } \pi=\frac{\dot{P}}{P}
$$

Assim, a variação na oferta real de moeda é igual ao imposto inflacionário, de modo que, à medida que o governo aumenta a oferta de moeda, este obterá uma receita derivada desse imposto que depende do volume dos depósitos.

Utilizando-se a restrição orçamentária dos bancos:

$$
M_{t}=\varepsilon_{t} D_{t}
$$

Dividindo ambos os lados da equação (22) por $P_{t}$, temos que:

$$
\frac{M_{t}}{P_{t}}=\varepsilon_{t} \frac{D_{t}}{P_{t}}
$$




$$
\frac{M_{t}}{P_{t}}=\varepsilon_{t} d_{t}
$$

Assumimos que a restrição orçamentária do governo seja:

$$
g_{t}=\mu_{t}\left(\pi \frac{\bar{M}_{t}}{P_{t}}\right)
$$

ou,

$$
g_{t}=\mu_{t}\left(\pi \varepsilon d_{t}\right)
$$

Assim, a receita do imposto inflacionário é utilizada para financiar os investimentos do governo em infra-estrutura, sendo que o determinante da proporção do imposto inflacionário que será gasto pelo governo dependerá de $\mu$, que está entre $[0,1]$. Para o caso em que $\mu$ é igual a 1 , a totalidade do imposto inflacionário será gasta pelo governo na provisão de infra-estrutura. Porém, se $\mu$ for igual a 0 , o imposto inflacionário terá efeitos negativos sobre a economia, visto que as receitas do governo com o imposto inflacionário não serão revertidas à população sob a forma de investimentos em infra-estrutura.

Os gastos do governo $\left(g_{t}\right)$ também podem ser escritos como:

$$
g_{t}=\mu \pi\left(\frac{M}{P}\right)=\mu \frac{\dot{M}}{P}
$$

que podem ainda ser representados por:

$$
g_{t}=\mu \pi \varepsilon d_{t}
$$

Como os investimentos do governo representam investimentos em infra-estrutura e, segundo a equação (1), trata-se de um insumo de produção, o objetivo aqui será escrever $(g)$ como uma fração de $(k)$.

A partir da equação (14), temos que:

$$
\begin{aligned}
& L_{t}=D_{t}-M_{t} \\
& L_{t}=D_{t}-\varepsilon_{t} D_{t} \\
& L_{t}=\left(1-\varepsilon_{t}\right) D_{t}
\end{aligned}
$$


Dividindo ambos os lados por $P_{t}$ obtemos:

$$
1_{t}=\left(1-\varepsilon_{t}\right) d_{t}
$$

Sabendo que todos os empréstimos em termos reais $\left(l_{t}\right)$ são convertidos em estoque de capital, encontramos:

$$
\begin{aligned}
& k_{t}=\left(1-\varepsilon_{t}\right) d_{t} \\
& k_{t} /\left(1-\varepsilon_{t}\right)=d_{t}
\end{aligned}
$$

Substituindo $d_{t}$ em (28), resulta em:

$$
g_{t}=\mu \frac{\pi \varepsilon}{(1-\varepsilon)} k_{t}
$$

Entretanto, como gé uma função de $k$, podemos reescrever a equação (1) da seguinte forma:

$$
y=f\left(k_{t}, \mu \frac{\pi \varepsilon}{(1-\varepsilon)} k_{t}\right)=f\left(k_{t}, \pi, \varepsilon\right)
$$

Por conseguinte, a produção da economia em $t$ depende do estoque de capital, do imposto inflacionário e das reservas bancárias. Assim, é possível verificar que o mercado monetário da economia está afetando o setor real, tanto pelas reservas bancárias, que afetam a quantidade de empréstimos destinada a investimento, como pelo imposto inflacionário, que determina o investimento do governo em infra-estrutura. De forma simplificada, é possível escrever a função de produção como sendo:

$$
y=f\left(k_{\text {privado, }}, k_{\text {público }}\right)
$$

A equação (1") implica que a produção da economia é uma função do montante de capital público e privado.

\subsection{Características do equilíbrio}

Uma vez desenvolvido o modelo básico, seguimos as afirmações de Basu (2001), que descreve as características do equilíbrio do sistema. Assim, após 
a solução das condições de equilíbrio para as firmas, bancos e governo, podemos passar a analisar as características do equilíbrio dessa economia que estão sumarizadas a seguir:

(i) Dados $\left(\mathrm{i}^{L}\right)$ e $\left(P_{t}\right)$, as firmas solucionam a equação (6) e determinam $\left(K_{t}\right)$;

(ii) A condição de lucro zero dos bancos significa que a equação (16) será mantida;

(iii) Desde que todo capital é intermediado, a equação (11') se mantém, ou seja, a taxa de juros real sobre os empréstimos é igual ao produto marginal do capital; e

(iv) Dado o conhecimento total de $\left(d_{t}\right)$, o Banco Central mantém a seqüência de oferta de moeda que determina a trajetória dos preços no tempo $\left(P_{t}\right)$, que satisfaça a equação (18).

Sendo assim, é possível partirmos para a solução de equilíbrio geral do modelo, que consiste na escolha do montante de depósitos ótimos das famílias nos bancos. Assumindo que a função utilidade das famílias possui a forma de comportamento de aversão relativa ao risco constante, significando $u\left(c_{t}\right)=c_{t}^{1-\gamma} / 1-\gamma$, o problema das famílias consiste em maximizar a função de preferência:

$$
\int_{0}^{\infty} e^{\rho t} \frac{c_{t}^{1-y}}{(1-y)}
$$

na qual $\gamma>0 \mathrm{e}<1$.

Sujeito à restrição

$$
c_{t}+\dot{d}_{t}=\left[\left(i_{t}{ }^{d}-\frac{\dot{P}_{t}}{P_{t}}\right) d_{t}+w_{t}\right]
$$

Utilizando-se o fato de que:

$$
i^{L}=\frac{i^{D}}{(1-\varepsilon)}
$$

A equação (34) pode ser reescrita como:

$$
d_{t}=\left[i_{t}^{l}\left(1-\varepsilon_{t}-\pi_{t}\right) d_{t}+w_{t}-c_{t}\right]
$$


A partir da equação (35), é possível verificarmos que um aumento nas reservas bancárias e no imposto inflacionário reduz a remuneração efetiva dos depósitos dos agentes econômicos e, portanto, sua renda.

O Hamiltoniano ${ }^{1}$ resultante do problema de maximização intertemporal é dado por:

$$
H e^{-\rho t}=\frac{c_{t}{ }^{1-\gamma}}{(1-\gamma)}+\lambda\left[i_{t}^{l}\left(1-\varepsilon_{t}-\pi_{t}\right) d_{t}+w_{t}-c_{t}\right]
$$

Primeiramente, devemos encontrar as condições de primeira ordem, que são:

$$
\begin{aligned}
& \frac{\partial H}{\partial c}=c^{-y}-\lambda=0 \quad \Rightarrow \text { ou } \lambda=c^{-y} \\
& \frac{\partial H}{\partial d_{t}}=\lambda\left[\left(i_{t}^{l}\left(1-\varepsilon_{t}\right)-\pi_{t}\right)\right]=0 \\
& \text { Como } \dot{\lambda}=\lambda \rho-\frac{\partial H}{\partial d_{t}} \text { temos que: } \\
& \dot{\lambda}=\lambda \rho-\lambda\left[i_{t}^{l}\left(1-\varepsilon_{t}\right)-\pi_{t}\right] \\
& \frac{\dot{\lambda}}{\lambda}=\rho-\left[i_{t}^{l}\left(1-\varepsilon_{t}\right)-\pi_{t}\right]
\end{aligned}
$$

Para encontrarmos a taxa de crescimento do consumo, temos que:

$$
\begin{aligned}
& \frac{\partial c^{-y}}{d_{t}}=\frac{\partial y}{\partial t} \\
& -y c^{-1-y} \dot{c}=\dot{\lambda} \\
& -y \frac{\dot{c}}{c} c^{-y}=\dot{\lambda}
\end{aligned}
$$

Considerando que $c^{-\gamma}=\lambda$, podemos reescrever a equação anterior da seguinte forma:

$$
-y \frac{\dot{c}}{c}=\frac{\dot{\lambda}}{\lambda}
$$


$\frac{\dot{c}}{c}=-\frac{1}{\gamma} \frac{\dot{\lambda}}{\lambda}$

Substituindo a equação (41) na equação anterior, obtemos:

$\frac{\dot{c}}{c}=\frac{1}{\gamma}\left\{\rho-\left[i_{t}^{l}\left(1-\varepsilon_{t}\right)-\pi_{t}\right]\right\}$

Rearranjando, temos:

$$
\begin{aligned}
& \frac{\dot{c}}{c}=\frac{\left[i_{t}^{l}\left(1-\varepsilon_{t}\right)-\pi_{t}\right]-\rho}{\gamma} \\
& \frac{\dot{c}}{c}=\frac{\left[i_{t}^{l}-i_{t}^{l} \varepsilon_{t}-\pi_{t}\right]-\rho}{\gamma}
\end{aligned}
$$

Utilizando o fato de que $i_{t}^{l}-\pi_{t}=f_{k}\left(k_{t}, \pi, \varepsilon_{t}\right)$, é possível reescrever $\left(46^{\prime}\right)$ como:

$$
\frac{\dot{c}}{c}=\frac{\left[f_{k}^{\prime}\left(k_{t}, \pi, \varepsilon_{t}\right)-i_{t}^{l} \varepsilon_{t}\right]-\rho}{\gamma}
$$

Pela equação (10'), sabemos que:

$i_{t}^{l}=f\left(k_{t}, \pi, \varepsilon_{t}\right)+\varepsilon_{t}$

Assim, isso nos permite reescrever a equação (47) ainda como:

$$
\frac{\dot{c}}{c}=\frac{\left.\left[f_{k}\left(k_{t}, \pi, \varepsilon\right)-\left(f_{k}\left(k_{t}, \pi_{t}, \varepsilon_{t}\right)+\pi\right) \varepsilon_{t}\right)\right]-\rho}{\gamma}
$$

Rearranjando a equação anterior, encontramos que:

$$
\frac{\dot{c}}{c}=\frac{\left[f_{k}\left(k_{t}, \pi, \varepsilon\right)-\left(f_{k}\left(k_{t}, \pi_{t}, \varepsilon_{t}\right) \varepsilon_{t}+\pi \varepsilon_{t}\right)\right]-\rho}{\gamma}
$$

Como $r_{t}=f_{k}\left(k_{t}, \pi, \varepsilon\right)$, isto nos possibilita encontrar a equação final que descreve a taxa de crescimento de equilíbrio do consumo desse modelo:

$$
\frac{\dot{c}}{c}=\frac{\left[r_{t}\left(-1-\varepsilon_{t}\right)-\pi_{T} \varepsilon_{t}-\rho\right]}{\gamma}
$$


O termo $\left[f^{\prime}\left(k_{t}\right)\left(1-\varepsilon_{t}\right)-\pi_{t} \varepsilon_{t}\right]$ da equação (48) é a taxa de retorno real sobre o portfólio dos bancos, que é também o retorno para os depositantes. O portfólio dos bancos consiste em empréstimos e reservas, e desde que as reservas pagam juros nominais zero, a taxa real de retorno sobre as reservas é o negativo da taxa de inflação. O requerimento de reservas impõe dois tipos de custos sobre o portfólio dos bancos. Primeiramente, este tributa o retorno real sobre o capital, visto que os bancos restringem os empréstimos para as firmas por causa do requerimento de reservas. Segundo, as reservas bancárias estão sujeitas ao imposto inflacionário, que é capturado pelo ter$\operatorname{mo} \pi_{t} \varepsilon_{t}$.

A condição de equilíbrio geral nos permite reescrever a equação final do modelo na forma estrutural:

$$
g_{c}=\frac{1}{\gamma} r_{t}\left(-1-\varepsilon_{t}\right)-\frac{1}{\gamma} \pi \varepsilon_{t}-\frac{\rho}{\gamma}
$$

ou ainda

$$
g_{c}=\frac{1}{\gamma} r_{t}-\frac{1}{\gamma} r_{t} \varepsilon_{t}-\frac{1}{\gamma} \pi \varepsilon_{t}-\frac{\rho}{\gamma}
$$

Assim, a taxa de crescimento da economia $\left(g_{c}\right)$ é influenciada pela taxa de juros, reservas bancárias, imposto inflacionário e a constante representada pelo termo $(\rho / \gamma)$. Esta, portanto, é a equação que será estimada no modelo econométrico. Apesar de essa equação representar a condição de estado estável, que implica que as variáveis estão crescendo a uma taxa constante, buscaremos mostrar com os testes empíricos como as variáveis se comportam diante de possíveis eventos que as façam desviar-se de seu estado de crescimento equilibrado.

\section{O MODELO ECONOMÉTRICO}

Na seção anterior, o modelo teórico demonstrou os efeitos da política monetária, em especial da taxa de juros, reservas bancárias e imposto inflacionário sobre a taxa de crescimento da economia. Assim, a equação (50) resultante do modelo é estimada nesta seção. Como temos um modelo de crescimento endógeno e as variáveis se inter-relacionam no tempo, optamos por estimar 
um modelo VAR da equação mencionada. A seguir, faremos uma breve análise dos dados e, posteriormente, apresentaremos o método econométrico a ser empregado, a estimativa e a discussão dos resultados do trabalho.

\subsection{Análise univariada das séries}

Nesta subseção fazemos, primeiramente, uma análise do comportamento das séries e a seguir realizamos testes para a ordem de integração das variáveis utilizadas nas estimações.

Para a estimação do modelo em questão, utilizamos séries temporais compostas de dados trimestrais que compreendem o período entre o primeiro trimestre de 1980 e o terceiro trimestre de 2003. No modelo, as variáveis são: taxa de crescimento do Produto Interno Bruto real (GPIB), taxa de juros over-Selic nominal (I), razão depósito compulsório/base monetária (RB) e o imposto inflacionário (IF), que foi calculado pelo Ipeadata segundo o método 2B proposto por Rocha e Saldanha (1995). A série RB foi coletada no Banco Central do Brasil (Bacen, 2004) e os demais dados tiveram como fonte o Instituto de Pesquisa Econômica Aplicada (Ipeadata, 2004). As séries utilizadas no trabalho encontram-se ilustradas na figura 1.

Com relação ao comportamento da taxa de crescimento do PIB, observamos que essa série oscila entre valores positivos e negativos, mas sempre em torno de uma média, não apresentando mudanças acentuadas ao longo do período em análise. Já quanto às séries imposto inflacionário e taxa de juros nominal, podemos verificar uma mudança de comportamento após o Plano Real, ${ }^{2}$ em 1994, visto que a brusca redução da inflação levou a uma queda significativa dessas variáveis. Comportamento contrário pode ser observado na série que ilustra as reservas bancárias, tendo em vista que no período posterior ao Plano Real estas foram elevadas com o intuito de impedir que o nível de preços voltasse a se acelerar. Para evitar que a mudança de comportamentos dessas séries prejudique nossa análise, utilizaremos variáveis Dummies na tentativa de corrigir possíveis vieses.

Ainda com o objetivo de mostrar o comportamento das séries, a tabela 1 apresenta a média, os valores máximo e mínimo e o desvio padrão de cada série.

Avaliando a tabela 1, verificamos que, ao longo do período estudado, o valor médio da série taxa de crescimento do PIB foi de 0,003 e os valores má- 
Tabela 1: Descrição estatística das séries

\begin{tabular}{lcccc}
\hline & GPIB & IF & RB & I \\
\hline Média & 0,0034 & 9,4961 & 0,3621 & 11,147 \\
\hline Valor máximo & 0,2012 & 59,649 & 0,6345 & 62,133 \\
\hline Valor mínimo & $-0,200$ & $-1,538$ & 0,2002 & 1,1795 \\
\hline Desvio padrão & 0,0748 & 9,6317 & 0,1027 & 12,848 \\
\hline
\end{tabular}

Fonte: Dados da pesquisa feita pelos autores.

Obs.: Número de lags = 5; número de observações $=90$.

ximos e mínimos foram, respectivamente, $0,201 \mathrm{e}-0,2$. Já quanto à série do imposto inflacionário, verificamos que a média no período foi de 9,50, com valor máximo de 59,65 e mínimo de - 1,54. Na série que mostra a evolução da razão reservas bancárias/base monetária, observamos um valor médio de 0,36 e valores máximo e mínimo de, respectivamente, 0,63 e 0,20. Por fim, a taxa de juros média do período foi de 11,15 , o valor máximo atingido foi 62,13 e o valor mínimo, 1,18 .

Dando continuidade à análise das séries temporais, é preciso verificar se o comportamento das variáveis utilizadas é ou não estacionário ao longo do tempo. Isso porque a utilização dos modelos de regressão envolvendo séries temporais não estacionárias pode conduzir ao problema de regressão espúria. Assim, se for detectada a presença de raiz unitária, deve-se trabalhar com as séries temporais diferenciadas e não em nível, ou seja, é necessário que a tendência da série seja removida.

Para que uma série temporal seja estacionária, suas médias, variâncias e covariâncias devem permanecer as mesmas, independentemente do período de tempo em que sejam medidas. A condição de estacionariedade é violada quando os dados apresentam tendências que sigam trajetórias ascendentes ou descendentes ao longo do tempo. ${ }^{3}$

A não-estacionariedade de um processo estocástico é uma conseqüência da existência de raiz unitária no processo auto-regressivo que gera a variável. Dessa forma, testes sobre a hipótese de raiz unitária desempenham um papel importante, pois podem auxiliar a avaliar a natureza da não-estacionariedade que a maior parte das séries econômicas apresenta. Assim, testar a estacionariedade das séries é fundamental para aplicações empíricas envolvendo séries macroeconômicas. 
Figura 1: Séries utilizadas no modelo
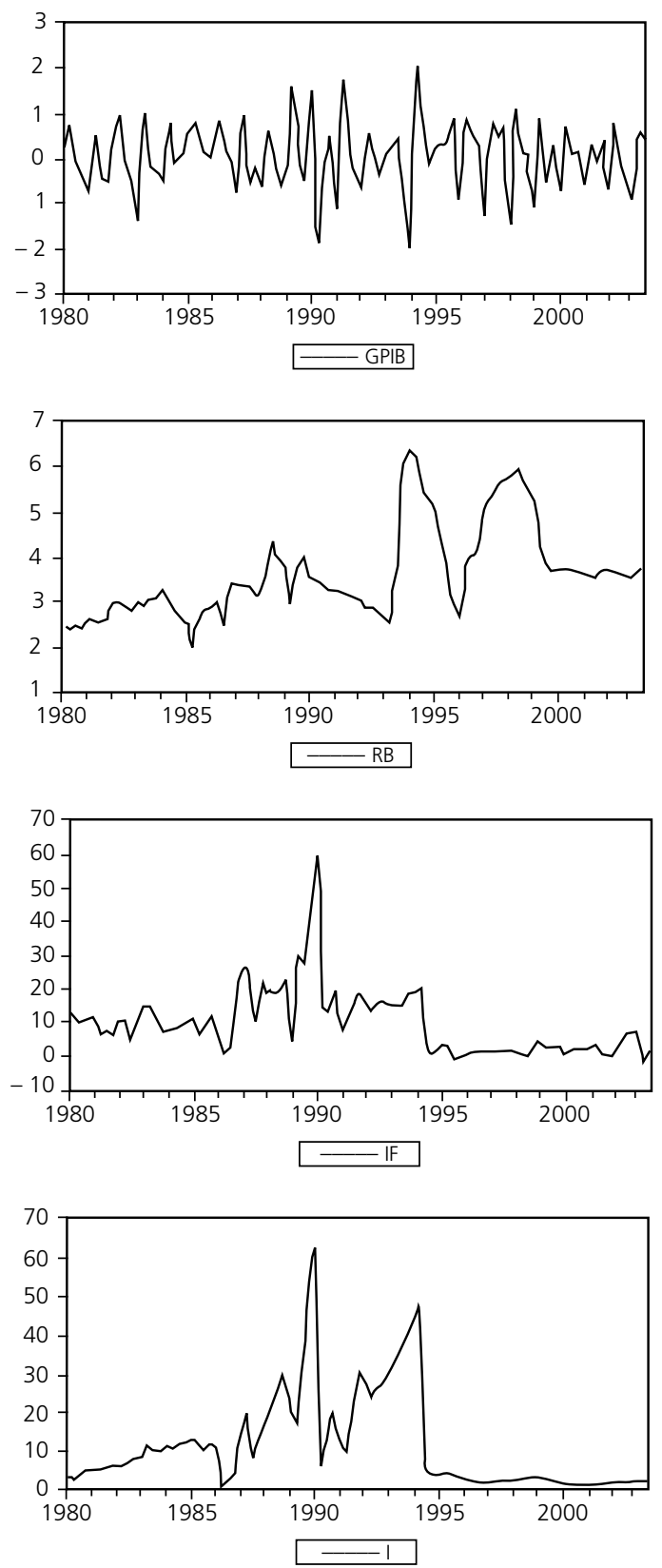
Deste modo, para verificarmos se as séries possuem raízes unitárias, utilizaremos inicialmente o teste de Dickey-Fuller Aumentado (ADF) proposto por Said e Dickey (1984). Este inclui termos de diferença defasados e possui a vantagem de considerar a autocorrelação entre os resíduos, sendo aplicado mediante o do seguinte modelo:

$$
\Delta Y_{t}=\beta_{1}+\beta_{2} t+\delta Y_{t-1}+\alpha_{i} \sum_{i=1}^{m} \Delta Y_{t-1}+\varepsilon_{t}
$$

Em cada caso, a hipótese nula é de que $\delta$ seja igual a 0 , ou seja, há uma raiz unitária indicando que os dados não são estacionários. Se o valor absoluto calculado da estatística $\tau$ excede os valores críticos absolutos de $\tau$ tabelado, então não se rejeita a hipótese de que a série temporal seja estacionária. Se, por outro lado, ele for menor que o valor crítico, a série temporal é não estacionária.

Nesse contexto, o teste de Phillips-Perron (PP), proposto por Phillips e Perron (1988), também objetiva identificar se as séries do modelo são estacionárias. Enquanto o teste ADF faz a correção para a maior ordem de correlação serial por adicionar termos defasados diferenciados no lado direito da equação, o teste de Phillips-Perron faz uma correção para a estatística-t do coeficiente de regressão $\operatorname{AR}(1)$ considerando a correlação serial. A hipótese nula do teste PP é a mesma do teste ADF. Tanto para o teste ADF como para o teste PP os valores críticos são os tabelados por Dickey-Fuller e MacKinnon (1991).

A tabela 2 sintetiza os resultados dos testes de Dickey-Fuller (ADF) e de Phillips-Perron (PP), cujo número de defasagens igual a 5 foi selecionado pelo critério de Akaike.

De acordo com a tabela 2, o teste ADF rejeita a presença de raiz unitária, ao nível de significância de 1\%, para as séries taxa de crescimento do PIB e imposto inflacionário, e ao nível de 5\% para as séries taxa de juros e reservas bancárias, indicando que as séries utilizadas são estacionárias. Da mesma forma, o teste de Phillip-Perron rejeita a presença de raiz unitária nas séries taxa de crescimento do PIB e imposto inflacionário, com 1\% de significância, na série da taxa de juros, com $5 \%$ de significância, e na série das reservas bancárias, com $10 \%$ de significância, confirmando a estacionariedade das séries utilizadas no modelo. 


\subsection{Estimação do modelo VAR}

Nesta subseção, os efeitos dos choques nos agregados monetários sobre o PIB são estimados através do modelo Auto-Regressivo Vetorial (VAR). Na estimação desse modelo é preciso que as séries temporais sejam estacionárias, o que foi demonstrado anteriormente. Nesse tipo de modelo, uma variável escalar é expressa em termos de uma combinação linear dos seus valores defasados e de todas as outras variáveis incluídas no modelo. Em termos práticos, as equações VAR especificam um sistema em que suas variáveis são movimentadas por choques correlacionados. Desta forma, há uma simultaneidade entre o conjunto de variáveis, não devendo haver qualquer distinção a priori (Enders, 1995).

$\mathrm{Na}$ especificação do modelo, foram introduzidos o termo constante e os valores defasados de cada variável em cada equação. Dessa forma, o modelo efetivo a ser estimado é:

$$
\begin{gathered}
G P I B_{t=} \alpha+\sum_{j=1}^{i} \beta_{j} G P I B_{t-1+} \sum_{j=1}^{i} \gamma_{j} I F_{t-1+} \sum_{j=1}^{i} \phi_{j} R B_{t-1+} \sum_{j=1}^{i} \phi_{j} I_{t-1} v_{l t} \\
I F_{t=} \alpha_{+} \sum_{j=1}^{i} \beta_{j} G P I B_{t-1+} \sum_{j=1}^{i} \gamma_{j} I F_{t-1+} \sum_{j=1}^{i} \phi_{j} R B_{t-1+} \sum_{j=1}^{i} \phi_{j} I_{t-1} v_{l t} \\
R B_{t=} \alpha+\sum_{j=1}^{i} \beta_{j} G P I B_{t-1+} \sum_{j=1}^{i} \gamma_{j} I F_{t-1+} \sum_{j=1}^{i} \phi_{j} R B_{t-1+} \sum_{j=1}^{i} \phi_{j} I_{t-1} v_{l t} \\
I_{t=} \alpha+\sum_{j=1}^{i} \beta_{j} G P I B_{t-1+} \sum_{j=1}^{i} \gamma_{j} I F_{t-1+} \sum_{j=1}^{i} \phi_{j} R B_{t-1+} \sum_{j=1}^{i} \phi_{j} I_{t-1} v_{l t}
\end{gathered}
$$

em que GPIB representa a taxa de crescimento do PIB, IF o imposto inflacionário, $\mathrm{RB}$ as reservas bancárias, I a taxa de juros, $\alpha$ a constante e $v_{t}$ os termos de erro estocástico, chamados de impulsos ou inovações na linguagem do VAR. ${ }^{4}$

Tabela 2: Testes de raiz unitária

\begin{tabular}{lccccc}
\hline Variável & $\begin{array}{c}\text { Dickey-Fuller } \\
\text { (ADF) }\end{array}$ & $\begin{array}{c}\text { Phillips-Perron } \\
\text { (PP) }\end{array}$ & $\begin{array}{c}\text { Valor crítico a } \\
\mathbf{1} \%\end{array}$ & $\begin{array}{c}\text { Valorcrítico a } \\
\mathbf{2} \%\end{array}$ & $\begin{array}{c}\text { Valor crítico a } \\
10 \%\end{array}$ \\
\hline $\mathrm{PIB}$ & $-8,81$ & $-18,20$ & $-3,45$ & $-2,89$ & $-2,58$ \\
\hline $\mathrm{IF}$ & $-4,05$ & $-3,90$ & $-3,45$ & $-2,89$ & $-2,58$ \\
\hline $\mathrm{RB}$ & $-3,06$ & $-2,60$ & $-3,45$ & $-2,89$ & $-2,58$ \\
\hline $\mathrm{I}$ & $-3,38$ & $-3,27$ & $-3,45$ & $-2,89$ & $-2,58$ \\
\hline
\end{tabular}

Fonte: Dados da pesquisa feita pelos autores.

Obs.: Número de lags $=5$; número de observações $=90$. 
Para iniciar a estimativa do modelo VAR, realizamos o teste de Critério de Seleção do Número de Defasagens (Var lag Order Selection Criteria) com o objetivo de verificar em quantos períodos as variáveis devem ser defasadas. A tabela 3 apresenta os resultados do teste de Critério de Seleção do Número de Defasagens.

Segundo a tabela 3, é possível verificarmos que os critérios sequential modified LR test, Final prediction error statistic e Akaike information indicaram que o número adequado de defasagens a ser utilizado no modelo VAR é cinco. O resultado da estimação do modelo VAR é apresentado na tabela 4.

Antes de iniciarmos a análise do VAR estimado na forma precedente, é relevante verificarmos se todas as variáveis que a priori consideramos endógenas podem ser tratadas como exógenas ao modelo estimado.

Para solucionar esse problema, na próxima seção trataremos dos conceitos e estimações referentes às exogeneidades fraca e forte.

\subsection{Testes de exogeneidade}

A importância de se verificar a exogeneidade fraca decorre do fato de se assumir que uma variável é exógena ao modelo quando, na verdade, ela não é. A implicação disso é que, em modelos uniequacionais, quando se assume que as variáveis do lado direito são exógenas, se tal não for verdade, a equação poderá ser melhorada por um sistema de equações.

O teste de exogeneidade que aplicamos baseia-se na tipologia definida por Engle et al. (1983). Essa metodologia consiste em, primeiramente, rodar uma regressão simples com a variável dependente em função de todas as variáveis exógenas que integram a equação do modelo. Os resíduos dessa equação, que é denominada equação condicional, devem ser retidos. Em seguida, é feita outra regressão entre a variável que acreditamos ser exógena contra suas defasagens, formando uma equação marginal. Novamente os erros devem ser extraídos. Esse procedimento é finalizado com uma regressão entre os resíduos da equação condicional $(u 1)$ e os resíduos da equação marginal ( $u 2)$, expressa na equação (57):

$$
u 1=c+\beta u 2
$$


Tabela 3: Teste do Critério de Seleção do Número de Defasagens

\begin{tabular}{lcccccc}
\hline Lag & logL & LR & FPE & AIC & SC & HQ \\
\hline 0 & $-440,0800$ & NA & 0,318935 & 10,20874 & 10,32211 & 10,25439 \\
\hline 1 & $-297,2170$ & 269,3049 & 0,017272 & 7,292345 & $7,859220^{*}$ & $7,520608^{*}$ \\
\hline 2 & $-278,7901$ & 33,04132 & 0,016375 & 7,236554 & 8,256930 & 7,647428 \\
\hline 3 & $-265,7506$ & 22,18224 & 0,017635 & 7,304610 & 8,778486 & 7,898095 \\
\hline 4 & $-237,0453$ & 46,19243 & 0,013318 & 7,012535 & 8,939911 & 7,788630 \\
\hline 5 & $-207,3257$ & $45,09175^{*}$ & $0,009897^{*}$ & $6,697142^{*}$ & 9,078019 & 7,655848 \\
\hline
\end{tabular}

Fonte: Dados da pesquisa feita pelos autores.

Obs.: (*) indica o número de lag selecionado por cada critério; LR: sequential modified; LR: test statistic (each test at $5 \%$ level); FPE: Final prediction error; AIC: Akaike information criterion; SC: Schwarz information criterion; HQ: Hannan-Quinn information criterion.

Devemos verificar se $\beta$ é significante ou não. Caso não seja, as equações são independentes, portanto, a variável em questão é exógena.

Como nosso objetivo nesta pesquisa é encontrar o impacto de variáveis monetárias sobre a taxa de crescimento da economia, a nossa análise de exogeneidade será restrita à primeira equação do VAR (equação 53). Sendo assim, queremos saber se alguma das variáveis que utilizamos como endógena pode ser exógena a essa equação do modelo VAR.

Após a realização da metodologia anteriormente descrita, chegamos aos resultados sintetizados na tabela 5 .

$\mathrm{Na}$ tabela 5, é possível verificarmos que a variável reservas bancárias é exogenamete fraca em relação ao modelo, pois o coeficiente do teste não se mostrou significativo, o que comprova a independência entre as equações condicional e marginal.

Além da exogeneidade fraca, podemos testar também a exogeneidade forte. A finalidade de verificarmos se a variável é exogenamente forte reside na capacidade de previsão do modelo.

A propriedade da exogeneidade forte exige dois pré-requisitos:

(i) exogeneidade fraca da variável; e

(ii) não-causalidade no sentido de Granger (1969).

Constatada a primeira exigência, ou seja, a de que a variável é exogenamente fraca, é preciso verificar a possível exogeneidade forte da variável. Para isso, basta apenas demonstrar a não-causalidade no sentido de Granger.

Vale ressaltar que o teste de Causalidade de Granger não determina se uma variável é exógena ou não. O teste serve apenas para determinar a pre- 
Tabela 4: Modelo VAR - variáveis endógenas

\begin{tabular}{|c|c|c|c|c|}
\hline & GPIB & IF & 1 & RB \\
\hline \multirow[t]{2}{*}{$\operatorname{GPIB}(-1)$} & $-0,294855$ & $-5,658149$ & $-22,89212$ & $-0,015130$ \\
\hline & $(0,10803)^{*}$ & $(12,1344)$ & $(11,5611)^{*}$ & $(0,06820)$ \\
\hline \multirow[t]{2}{*}{ GPIB $(-2)$} & $-0,185031$ & 30,69427 & 29,99657 & 0,095295 \\
\hline & $(0,11748)^{\star}$ & $(13,1957)^{*}$ & $(12,5722)^{*}$ & $(0,07417)$ \\
\hline \multirow[t]{2}{*}{ GPIB (-3) } & $-0,215127$ & 4,366727 & $-10,20993$ & 0,109460 \\
\hline & $(0,11833)^{*}$ & $(13,2914)$ & $(12,6633)$ & $(0,07470)$ \\
\hline \multirow[t]{2}{*}{ GPIB (-4) } & 0,415660 & 5,103133 & $-9,511731$ & $-0,020192$ \\
\hline & $(0,12008)^{*}$ & $(13,4876)$ & $(12,8503)$ & $(0,07581)$ \\
\hline \multirow[t]{2}{*}{ GPIB $(-5)$} & $-0,168253$ & 8,962544 & 19,94338 & 0,073401 \\
\hline & $(0,10825)$ & $(12,1591)$ & $(11,5846)^{*}$ & $(0,06834)$ \\
\hline \multirow[t]{2}{*}{$\operatorname{IF}(-1)$} & $-0,004699$ & 0,277577 & $-0,020350$ & 0,000595 \\
\hline & $(0,00150)^{*}$ & $(0,16844)^{\star}$ & $(0,16048)$ & $(0,00095)$ \\
\hline \multirow[t]{2}{*}{$\operatorname{IF}(-2)$} & 0,001533 & 0,119499 & $-0,107311$ & $-0,001341$ \\
\hline & $(0,00154)$ & $(0,17261)$ & $(0,16445)$ & $(0,00097)$ \\
\hline \multirow[t]{2}{*}{$\mathrm{IF}(-3)$} & 0,001994 & 0,345722 & 0,251704 & $-0,000505$ \\
\hline & $(0,00162)$ & $(0,18213)^{*}$ & $(0,17353)$ & $(0,00102)$ \\
\hline \multirow[t]{2}{*}{ IF $(-4)$} & $-0,007707$ & $-0,368176$ & $-0,520053$ & 0,000950 \\
\hline & $(0,00152)^{*}$ & $(0,17110)^{*}$ & $(0,16302)^{*}$ & $(0,00096)$ \\
\hline \multirow[t]{2}{*}{ IF $(-5)$} & 0,005608 & 0,406761 & 0,570663 & 0,001249 \\
\hline & $(0,00163)^{*}$ & $(0,18286)^{*}$ & $(0,17422)^{*}$ & $(0,00103)$ \\
\hline \multirow[t]{2}{*}{ I (-1) } & 0,001931 & 0,486539 & 0,946262 & $-0,000807$ \\
\hline & $(0,00141)$ & $(0,15796)^{*}$ & $(0,15050)^{*}$ & $(0,00089)$ \\
\hline \multirow[t]{2}{*}{ I (-2) } & $-0,002725$ & $-0,338215$ & $-0,213175$ & 0,000461 \\
\hline & $(0,00143)^{*}$ & $(0,16058)^{\star}$ & $(0,15299)$ & $(0,00090)$ \\
\hline I (-3) & 0,001709 & $-0,177366$ & $-0,155473$ & $9,90 \mathrm{E}-05$ \\
\hline
\end{tabular}

cedência temporal de uma variável sobre a outra. Assim, quando se afirma que $X$ causa $Y$ no sentido de Granger, está-se apenas afirmando que $X$ precede temporalmente $Y$ (Granger, 1969).

Sendo assim, para testarmos se a variável reservas bancárias é exogenamente forte ao modelo, realizamos o teste de Causalidade de Granger, cujos resultados são apresentados na tabela 6 .

Observando a tabela 6, não é possível rejeitarmos a hipótese nula do teste de Causalidade de Granger para a variável reservas bancárias (RB), tendo em vista que a probabilidade de que essa variável não cause taxa de crescimento do PIB (GPIB), no sentido de Granger, é de 69\%. Também podemos constatar que GPIB não causa RB no sentido de Granger com uma probabilidade 
Tabela 4: Modelo VAR - variáveis endógenas (cont.)

\begin{tabular}{|c|c|c|c|c|}
\hline & GPIB & IF & I & RB \\
\hline & $(0,00146)$ & $(0,16387)$ & $(0,15613)$ & $(0,00092)$ \\
\hline \multirow[t]{2}{*}{ I (-4) } & 0,000729 & 0,295715 & 0,593534 & 0,000119 \\
\hline & $(0,00134)$ & $(0,15099)^{*}$ & $(0,14386)^{*}$ & $(0,00085)$ \\
\hline \multirow[t]{2}{*}{$I(-5)$} & $-0,000411$ & $-0,307256$ & $-0,506849$ & $-0,001451$ \\
\hline & $(0,00127)$ & $(0,14300)^{*}$ & $(0,13624)^{*}$ & $(0,00080)^{*}$ \\
\hline \multirow[t]{2}{*}{$\mathrm{RB}(-1)$} & $-0,367347$ & 19,77061 & 33,07949 & 1,105201 \\
\hline & $(0,15363)^{\star}$ & $(17,2564)$ & $(16,4411)^{\star}$ & $(0,09699)$ \\
\hline \multirow[t]{2}{*}{$\mathrm{RB}(-2)$} & $-0,409602$ & $-30,57403$ & $-19,03993$ & $-0,095346$ \\
\hline & $(0,24384)^{*}$ & $(27,3894)$ & $(26,0952)$ & $(0,15394)$ \\
\hline \multirow[t]{2}{*}{$\mathrm{RB}(-3)$} & $-0,178348$ & $-60,03599$ & $-110,7574$ & $-0,068050$ \\
\hline & $(0,24511)$ & $(27,5327)$ & $(26,2317)$ & $(0,15475)$ \\
\hline \multirow[t]{2}{*}{$\mathrm{RB}(-4)$} & 0,113643 & 115,8881 & 119,4874 & $-0,093216$ \\
\hline & $(0,25631)$ & $(28,7898)^{\star}$ & $(27,4294)^{*}$ & $(0,16181)$ \\
\hline \multirow[t]{2}{*}{$\mathrm{RB}(-5)$} & $-0,076495$ & $-54,80417$ & $-29,12974$ & 0,044881 \\
\hline & $(0,17099)$ & $(19,2071)^{*}$ & $(18,2996)^{\star}$ & $(0,10795)$ \\
\hline \multirow[t]{2}{*}{ C } & 0,051872 & 5,309415 & 3,842851 & 0,042426 \\
\hline & $(0,03348)$ & $(3,76112)$ & $(3,58340)$ & $(0,02114)^{*}$ \\
\hline \multirow[t]{2}{*}{ DummyRB } & 0,093943 & 6,879200 & 7,960799 & 0,045561 \\
\hline & $(0,04062)^{*}$ & $(4,56238)$ & $(4,34680)^{*}$ & $(0,02564)^{*}$ \\
\hline \multirow[t]{2}{*}{ Dummyl } & 0,020175 & 0,120515 & 6,303813 & 0,181312 \\
\hline & $(0,04529)^{*}$ & $(5,08668)^{*}$ & $(4,84633)$ & $(0,02859)^{*}$ \\
\hline $\mathrm{R}^{2}$ & 0,627847 & 0,723242 & 0,856227 & 0,917538 \\
\hline Estatística F & 4,841156 & 7,498933 & 17,08948 & 31,92913 \\
\hline
\end{tabular}

Fonte: Dados da pesquisa feita pelos autores.

Obs.: Os valores entre parêntese são as estatísticas T e $\left(^{*}\right)$ indica que a hipótese nula foi rejeitada com $10 \%$ de significância. Número de lags = 5; número de observações $=90$.

de 57\%. Assim, confirmamos que a variável RB não precede temporalmente a variável GPIB, como também a variável GPIB não precede a variável RB.

Portanto, a exogeneidade fraca da variável reservas bancárias associada à não-causalidade no sentido de Granger nos leva à constatação de que a política de reservas bancárias é fortemente exógena à equação (53) do sistema VAR, isto é, ela não depende da taxa de crescimento do PIB, como ocorre com as demais variáveis.

\subsection{Estimação do VAR com a variável reservas bancárias exógena}

Sabendo que a variável reservas bancárias é fortemente exógena ao modelo, nesta subseção apresentamos a estimação e análise de um modelo VAR 
considerando essa variável como exógena. Os resultados encontram-se representados na tabela 7 .

Primeiramente, é preciso ressaltar que a análise do VAR se restringirá à primeira equação do sistema, pois esta apresenta o efeito das variáveis monetárias sobre a taxa de crescimento da economia, que é o que objetivamos saber.

Nesta equação, é possível notar que a variável taxa de crescimento do PIB na primeira, segunda, terceira e quarta defasagens mostrou-se significativa ao nível de $10 \%$. Já a variável imposto inflacionário apresentou-se estatisticamente significante nas defasagens um, quatro e cinco. Quanto à variável taxa de juros, esta foi estatisticamente significante apenas na segunda defasagem.

As reservas bancárias têm um papel crucial nesse modelo; como variável exógena mostrou-se significante, sendo que o seu coeficiente de 0,12 permite calcularmos o efeito de uma política de redução nas reservas bancárias.

Tabela 5: Teste de exogeneidade

\begin{tabular}{lcccc}
\hline Variable & Coefficient & Std. Error & t-Statistic & Prob. \\
\hline RB & $-0,003026$ & 0,002307 & $-1,311639$ & 0,1931 \\
\hline IF & 0,001731 & 0,000731 & 2,368898 & 0,0200 \\
\hline I & 0,000424 & 0,000633 & 0,670395 & 0,0544 \\
\hline
\end{tabular}

Fonte: Dados da pesquisa feita pelos autores.

Obs.: Número de lags $=5$; número de observações $=90$.

Tabela 6: Teste de Causalidade de Granger

\begin{tabular}{lccc}
\hline Hipótese nula & Obs & F-Statistic & Probabilidade \\
\hline IF não causa no sentido de Granger GPIB & 90 & 8,07921 & $3,4 \mathrm{E}-06$ \\
\hline GPIB não causa no sentido de Granger IF & & 1,74366 & 0,13434 \\
\hline I não causa no sentido de Granger GPIB & 90 & 2,95048 & 0,01709 \\
\hline GPIB não causa no sentido de Granger I & & 4,47288 & 0,00122 \\
\hline RB não causa no sentido de Granger GPIB & 90 & 0,61140 & 0,69140 \\
\hline GPIB não causa no sentido de Granger RB & & 0,77533 & 0,57039 \\
\hline I não causa no sentido de Granger IF & 90 & 2,39817 & 0,04449 \\
\hline IF não causa no sentido de Granger I & & 4,58668 & 0,00100 \\
\hline RB não causa no sentido de Granger IF & 90 & 3,43432 & 0,00736 \\
\hline IF não causa no sentido de Granger RB & & 0,53399 & 0,74991 \\
\hline RB não causa no sentido de Granger I & 90 & 7,75340 & $5,6 E-06$ \\
\hline I não causa no sentido de Granger RB & & 0,25711 & 0,93501 \\
\hline
\end{tabular}

Fonte: Dados da pesquisa feita pelos autores.

Obs.: Número de lags = 5; número de observações $=90$. 
Usando o valor médio de 0,36 da variável RB (conforme a tabela 1), temos que uma redução em 10 pontos percentuais nessa variável, ou seja, de 0,36 para 0,26 , implica um impacto positivo de $1,2 \%\left(0,12^{\star} 0,36-0,12^{\star} 0,26=\right.$ 0,012), em média, na taxa de crescimento econômico. No entanto, uma elevação em RB de 10 pontos percentuais causa impacto negativo na mesma proporção na taxa de crescimento de longo prazo. Portanto, a política de reservas bancárias influencia a determinação de quanto da poupança das famílias será emprestado às firmas para ser convertido em aumento de capacidade produtiva de longo prazo.

As variáveis dummies, que tiveram o objetivo de capturar outliers, demonstraram ser significantes. Analisando economicamente seus significados, podemos afirmar que estas, no período em que foram inseridas, influenciam a constante da regressão que estima o valor médio da taxa de crescimento.

É importante frisarmos que, quando trabalhamos com VAR, cada coeficiente estimado poderá não ser estatisticamente significativo, possivelmente em razão da multicolinearidade, mas coletivamente eles podem ser significativos com base no teste $\mathrm{F}$ padrão, que para essas variáveis apresentouse estatisticamente significante ao nível de $1 \%$, como podemos verificar na tabela 7.

Outro importante aspecto desse modelo é o fato de que todas as variáveis significantes apresentaram o sinal previsto pelo modelo teórico. Quanto à taxa de juros, observamos que essa variável afetou negativamente a variabilidade da taxa de crescimento da economia brasileira durante o período estudado. Já quanto ao imposto inflacionário, verificamos que inicialmente seu efeito sobre a taxa de crescimento da economia é negativo e somente no quinto período esse efeito torna-se positivo. Esse fato demonstra existir uma certa defasagem entre o financiamento do governo através do imposto inflacionário e a reversão desses recursos para gastos do governo em infraestrutura, como preconiza o modelo teórico.

No que se refere ao coeficiente de determinação $\left(R^{2}\right)$, que mede a proporção da variável dependente que pode ser explicada pelas variáveis defasadas, observamos que esse valor foi de $61 \%$, indicamos que a proporção da variação da taxa de crescimento do PIB que pode ser explicada pelas variáveis incluídas no modelo é de $61 \%$. 
Tabela 7: Modelo VAR - RB exógena

\begin{tabular}{|c|c|c|c|}
\hline & GPIB & IF & 1 \\
\hline \multirow[t]{2}{*}{ GPIB (-1) } & $-0,317808$ & $-6,428698$ & $-27,03203$ \\
\hline & $(0,10514)^{*}$ & $(13,0905)$ & $(13,5340)^{*}$ \\
\hline \multirow[t]{2}{*}{ GPIB $(-2)$} & $-0,192487$ & 31,09192 & 31,25265 \\
\hline & $(0,11488)^{\star}$ & $(14,3024)^{*}$ & $(14,7869)^{\star}$ \\
\hline \multirow[t]{2}{*}{ GPIB $(-3)$} & $-0,229442$ & 7,935608 & $-5,133251$ \\
\hline & $(0,11531)^{*}$ & $(14,3562)$ & $(14,8426)$ \\
\hline \multirow[t]{2}{*}{ GPIB (-4) } & 0,390210 & 2,905905 & $-5,004888$ \\
\hline & $(0,11610)^{\star}$ & $(14,4548)$ & $(14,9446)$ \\
\hline \multirow[t]{2}{*}{ GPIB (-5) } & $-0,135846$ & 0,175758 & 15,94442 \\
\hline & $(0,10243)$ & $(12,7529)^{*}$ & $(13,1850)^{*}$ \\
\hline \multirow[t]{2}{*}{ IF $(-1)$} & $-0,004341$ & 0,376922 & 0,118126 \\
\hline & $(0,00146)^{*}$ & $(0,18123)^{*}$ & $(0,18737)$ \\
\hline \multirow[t]{2}{*}{ IF $(-2)$} & 0,000794 & 0,078722 & $-0,169628$ \\
\hline & $(0,00149)$ & $(0,18525)$ & $(0,19153)$ \\
\hline \multirow[t]{2}{*}{ IF $(-3)$} & 0,002468 & 0,307856 & 0,191994 \\
\hline & $(0,00158)$ & $(0,19726)$ & $(0,20394)$ \\
\hline \multirow[t]{2}{*}{ IF $(-4)$} & $-0,007660$ & $-0,429474$ & $-0,611425$ \\
\hline & $(0,00149)^{*}$ & $(0,18572)^{*}$ & $(0,19202)^{*}$ \\
\hline \multirow[t]{2}{*}{ IF $(-5)$} & 0,005094 & 0,526438 & 0,733406 \\
\hline & $(0,00153)^{*}$ & $(0,18999)^{*}$ & $(0,19642)^{*}$ \\
\hline \multirow[t]{2}{*}{ I (-1) } & 0,001448 & 0,337208 & 0,918468 \\
\hline & $(0,00122)$ & $(0,15136)^{*}$ & $(0,15649)^{*}$ \\
\hline \multirow[t]{2}{*}{ I (-2) } & $-0,002218$ & $-0,267347$ & $-0,255309$ \\
\hline & $(0,00133)^{*}$ & $(0,16503)^{*}$ & $(0,17062)^{*}$ \\
\hline \multirow[t]{2}{*}{ I (-3) } & 0,001522 & $-0,101461$ & $-0,056767$ \\
\hline & $(0,00144)$ & $(0,17902)$ & $(0,18508)$ \\
\hline \multirow[t]{2}{*}{ I (-4) } & 0,000747 & 0,320685 & 0,621449 \\
\hline & $(0,00133)$ & $(0,16601)^{*}$ & $(0,17163)^{*}$ \\
\hline \multirow[t]{2}{*}{ I (-5) } & $-0,000125$ & $-0,355271$ & $-0,570397$ \\
\hline & $(0,00119)$ & $(0,14790)^{*}$ & $(0,15291)^{*}$ \\
\hline \multirow[t]{2}{*}{$\mathrm{RB}$} & $-0,123393$ & $-6,821201$ & $-4,697826$ \\
\hline & $(0,06738)^{*}$ & $(8,38836)$ & $(8,67256)$ \\
\hline \multirow[t]{2}{*}{$\mathrm{C}$} & 0,062003 & 4,064241 & 2,937897 \\
\hline & $(0,02855)^{*}$ & $(3,55478)$ & $(3,67521)$ \\
\hline \multirow[t]{2}{*}{ Dummy I } & 0,024351 & 4,082354 & 9,818194 \\
\hline & $(0,04352)^{*}$ & $(5,41855)^{*}$ & $(5,60213)$ \\
\hline \multirow[t]{2}{*}{ Dummy RB } & 0,105161 & 2,786612 & 0,609506 \\
\hline & $(0,03864)^{\star}$ & $(4,81122)$ & $(4,97423)$ \\
\hline $\mathrm{R}^{2}$ & 0,610347 & 0,644005 & 0,782227 \\
\hline F- estatística & 5,770902 & 6,664831 & 13,23347 \\
\hline
\end{tabular}

Fonte: Dados da pesquisa feita pelos autores.

Obs.: Os valores entre parêntese são as estatísticas T e o símbolo $\left(^{*}\right)$ indica nível de significância de $10 \%$. Número de lags $=5$; número de observações $=90$. 
Ainda quanto à estimação do VAR, podemos analisar o comportamento da decomposição da variância do erro de previsão das variáveis, que indica a proporção do movimento na seqüência de uma variável em função do seu próprio choque puro versus os choques puros de outras variáveis que compõem o modelo VAR. Na tabela 8 apresentamos a decomposição da variância do erro para a variável taxa de crescimento do PIB.

Observamos na tabela 8 que no primeiro período a variação da taxa de crescimento do PIB deve-se $100 \%$ à sua própria variação. Já no décimo período, constatamos que $32 \%$ de sua variação deve-se ao imposto inflacionário e $13 \%$ à taxa de juros, enquanto choques na própria taxa de crescimento explicam agora 55\% dessa variância. Logo, os resultados comprovam que, após dez períodos, choques nas variáveis em estudo levam a movimentos na decomposição da variância do erro da taxa de crescimento do PIB.

Em seguida, passaremos a verificar o comportamento das funções impulso resposta, as quais permitem destacarmos a resposta em uma variável, dado um "impulso" em qualquer outra variável do sistema. Na figura 2 apresentamos a função impulso resposta para a variável taxa de crescimento do PIB com relação, primeiramente, a um choque nessa mesma variável e, em seguida, a um choque no imposto inflacionário e, por fim, a um choque na taxa de juros.

Avaliando a figura 2, é possível constatarmos que a variável taxa de crescimento do PIB, como era esperado, responde, de início, negativamente a um choque generalizado positivo na variável imposto inflacionário, o que se estende até o terceiro período. Em seguida, observamos uma recuperação, ou seja, um efeito positivo e, posteriormente, mais uma resposta negativa que dura até o sexto período. Após isso, o choque começa a ser dissipado e a variável taxa de crescimento do PIB retorna lentamente ao patamar inicial.

Quanto à resposta da variável GPIB a um choque generalizado positivo na variável taxa de juros, verificamos que a resposta é inicialmente negativa, se estendendo até o terceiro período. Na seqüência, observamos um efeito positivo e, novamente, um efeito negativo, cuja duração é até o sexto período. No décimo período, a taxa de crescimento do PIB volta ao seu nível inicial e o efeito do choque é neutralizado.

Por conseguinte, a função impulso resposta nos indica que a variável taxa de crescimento do PIB responde a choques nas variáveis monetárias 
Tabela 8: Decomposição da variância do GPIB

\begin{tabular}{lcccc}
\hline Período & S.E. & GPIB & IF & I \\
\hline 1 & 0,053751 & 100 & 0 & 0 \\
2 & 0,062726 & 87,22310 & 10,81201 & 1,964890 \\
\hline 3 & 0,065330 & 80,84025 & 10,36970 & 8,790041 \\
\hline 4 & 0,066700 & 77,88856 & 13,45002 & 8,661421 \\
\hline 5 & 0,077010 & 59,66804 & 31,62159 & 8,710378 \\
\hline 6 & 0,079900 & 56,87321 & 33,78135 & 9,345443 \\
\hline 7 & 0,080368 & 56,21449 & 34,16462 & 9,620888 \\
\hline 9 & 0,082479 & 54,41985 & 32,44542 & 13,13473 \\
\hline 10 & 0,083573 & 55,01696 & 32,12317 & 12,85987 \\
\hline
\end{tabular}

Fonte: Dados da pesquisa feita pelos autores.

Obs.: Número de lags = 5; número de observações $=90$.

imposto inflacionário e taxa de juros. Verificamos também a não-ocorrência de efeitos permanentes sobre a taxa de crescimento do PIB, ou seja, a taxa de juros e o imposto inflacionário atuam apenas sobre a variabilidade dessa taxa.

Para dar robustez aos resultados do modelo VAR estimado, realizamos o teste de autocorrelação para verificarmos se o modelo possui autocorrelação em seus resíduos. O resultado é ilustrado na tabela 9.

A hipótese nula do teste é que não existe autocorrelação serial nos resíduos do modelo. Desta forma, a não-rejeição da hipótese nula indica que não há autocorrelação nos resíduos dos regressores.

Faz-se necessário ainda verificarmos a normalidade dos erros. Para isso, utilizamos o teste de normalidade assintótica dos resíduos de Jarque-Bera, que compara os resíduos da equação aos resíduos da distribuição normal. Primeiramente, é necessário calcular a estatística de Jarque-Bera, que segue uma distribuição de $\chi^{2}$. A hipótese nula do teste é que os resíduos seguem uma distribuição normal, obedecendo, assim, à hipótese do modelo Clássico de Regressão Linear. Os resultados do teste são apresentados na tabela 10.

Na tabela 9 indicamos que a probabilidade de os erros em conjunto seguirem uma distribuição normal é de 39\%, apontando para a não-rejeição da hipótese nula do teste de Jarque-Bera, o que comprova que os erros seguem uma distribuição normal. 
Tabela 9: Teste de autocorrelação

\begin{tabular}{ccc}
\hline Defasagens & LM-Stat & Probabilidade \\
\hline 1 & 26,99578 & 0,0014 \\
\hline 2 & 13,47861 & 0,1421 \\
\hline 3 & 8,378848 & 0,4965 \\
\hline 4 & 5,201538 & 0,8164 \\
\hline 5 & 10,09214 & 0,3431 \\
\hline
\end{tabular}

Fonte: Dados da pesquisa - feita pelos autores.

Obs.: Número de lags = 5; número de observações $=90$.

Tabela 10: Teste de Jarque-Bera

\begin{tabular}{lccc}
\hline Componente & Jarque-Bera & df & Probabilidade \\
\hline GPIB & 3,145960 & 2 & 0,2074 \\
\hline IF & 1,269023 & 2 & 0,5302 \\
\hline I & 1,843024 & 2 & 0,3979 \\
\hline Total & 6,258007 & 6 & 0,3949 \\
\hline
\end{tabular}

Fonte: Dados da pesquisa - feita pelos autores.

Obs.: Número de lags $=5$; número de observações $=90$.

Figura 2: Função impulso resposta para a variável GPIB
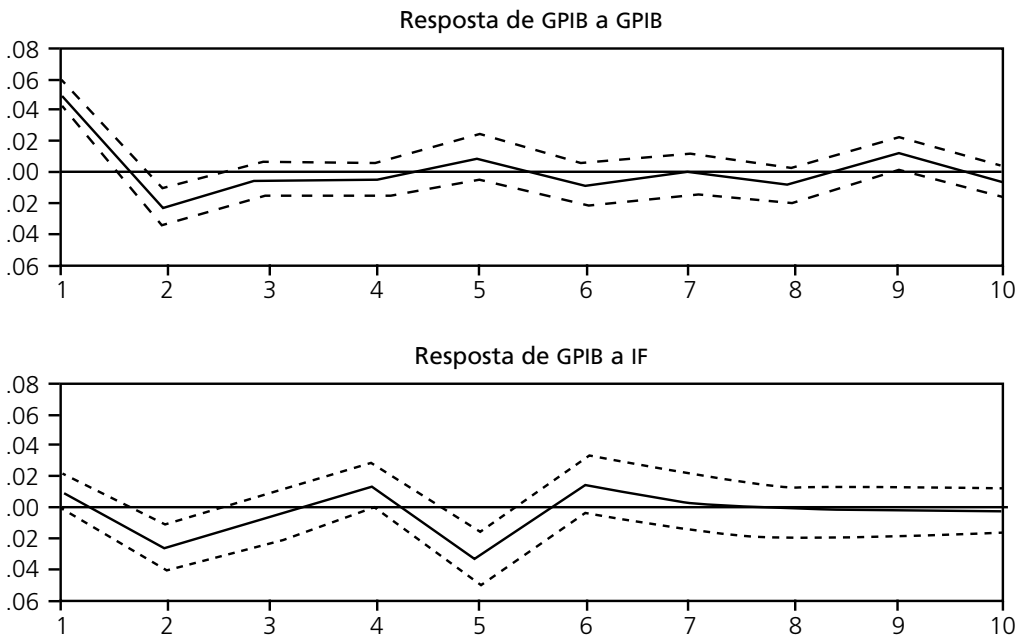

Resposta de GPIB a I

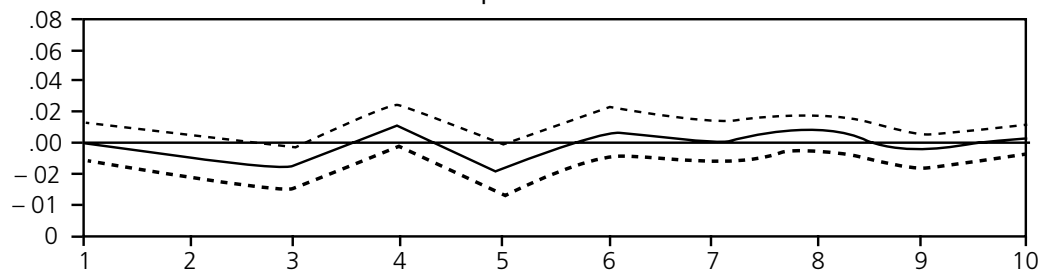

Fonte: Dados da pesquisa feita pelos autores. 
Figura 3: Teste de estabilidade do VAR

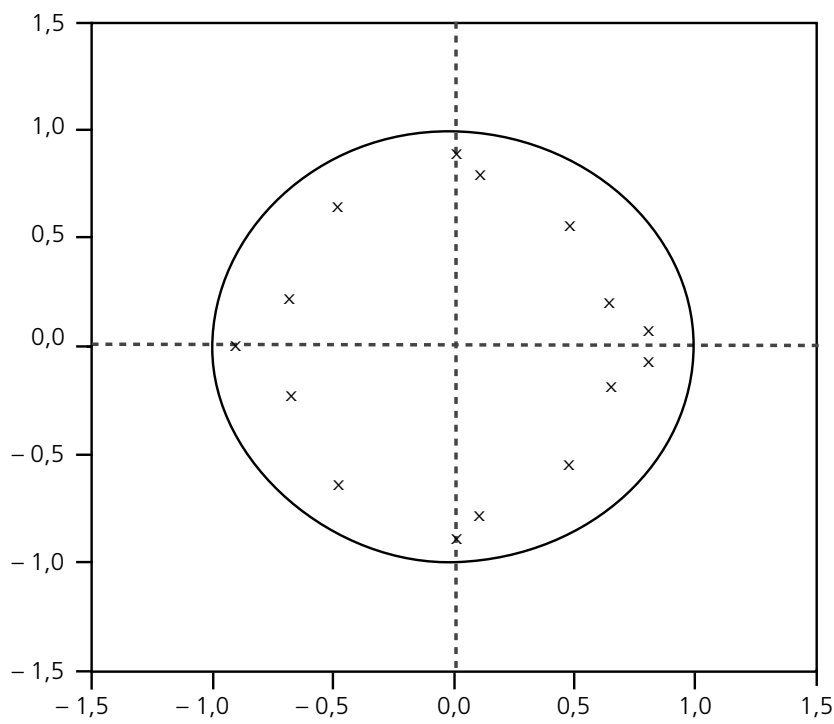

Fonte: Dados da pesquisa - feita pelos autores.

Obs.: Número de lags = 5; número de observações $=90$.

Por fim, devemos testar a estabilidade do VAR, ou seja, verificar se nenhuma das raízes excede a unidade. Na figura 3 apresentamos os resultados desse teste.

A figura 3, portanto, evidencia que nenhuma das raízes ultrapassa o círculo da unidade, comprovando que o VAR satisfaz a condição de estabilidade.

Os testes de autocorrelação, normalidade e estabilidade foram utilizados para garantir a confiabilidade das estimações realizadas em nosso modelo. Os resultados desses testes reforçaram a qualidade de nossas estimações.

Após a apresentação e discussão dos testes empíricos realizados, podemos passar às considerações finais deste trabalho.

\section{CONCLUSÃO}

A relação entre desenvolvimento financeiro e crescimento econômico tem se tornado uma questão de extensa análise e debate. A teoria sobre o assunto tem focado os serviços providos pela intermediação financeira, afirmando 
que eles são essenciais para a inovação e o desenvolvimento econômico. Isso ocorre porque a presença de intermediação financeira reduz a necessidade social de liquidez, aumenta a canalização da poupança para as atividades produtivas e permite aos agentes reduzirem o risco associado com suas necessidades de liquidez.

Em nosso modelo teórico, estabelecemos a interação entre quatro agentes - governo, firmas, setor bancário e famílias -, o que tornou o setor financeiro da economia endógeno, sendo que este passou a depender das decisões das famílias, a respeito de quanto manter nos bancos sob a forma de depósito, e do governo, a respeito de qual a política de reservas bancárias a ser adotada.

Como resultado, encontramos a relação entre crescimento econômico, imposto inflacionário, taxa de juros e reservas bancárias. Ao estimarmos essa relação para a economia brasileira, constatamos que um choque positivo nas variáveis monetárias taxa de juros e imposto inflacionário afetou negativamente a variabilidade da taxa de crescimento da economia no período estudado, não tendo, portanto, efeitos permanentes sobre essa taxa. Contudo, comprovamos que uma elevação na variável exógena reservas bancárias ocasionou reduções permanentes na taxa de crescimento da economia. Nossas estimações indicaram que a elevação em 10 pontos percentuais na alíquota de reservas bancárias reduz a taxa de crescimento da economia em até $1,2 \%$.

Sendo assim, podemos afirmar, com base em nossa análise empírica, que as variáveis monetárias taxa de juros, imposto inflacionário e reservas bancárias afetaram de alguma forma a taxa de crescimento da economia no período estudado. Outro resultado importante é a exogeneidade das reservas bancárias nesse processo. Isso nos permite ressaltar que ela age como um importante fator na alocação de recursos pelo setor financeiro na economia. A sua exogeneidade dita o comportamento do setor financeiro a partir da determinação do spread entre as taxas de juros de remuneração das famílias e dos juros sobre os empréstimos adquiridos pela firmas.

Em conseqüência, a maior imposição de reservas tem efeitos deletérios sobre a taxa de crescimento da economia. O crescimento é afetado porque a imposição de uma alíquota mais elevada de reservas aos bancos impõe um imposto à acumulação de capital. 


\section{NOTAS}

1. A esse respeito, ver Alpha Chiang (1992).

2. Sobre o Plano Real, ver Bacha (1997).

3. Ver Enders (1995).

4. Na estimação do modelo VAR, optamos por considerar separadamente a variável reservas bancárais em vez de multilicá-la pela taxa de juros como indicado na equação 50 . Isso foi feito com o intuito de evitar o problema de colinearidade, visto que a variável taxa de juros também faz parte do sistema.

\section{REFERÊNCIAS BIBLIOGRÁFICAS}

ARRAES, R. A., TELES, V. K. “Endogeneidade e exogeneidade do crescimento econômico: uma análise comparativa entre Nordeste, Brasil e países selecionados". Revista Econômica do Nordeste, 31 (n. especial), p. 754-776. Trabalho apresentado no V Encontro Regional de Economia.

BACEN - Banco Central do Brasil. Disponível em: $<$ http://www.bcb.gov.br.htm > Acesso em 20/9/2004.

BACHA, E. (1997) “Plano Real: uma avaliação”. In: Mercadante, A. (coord.). O Brasil Pós-Real. Campinas: Unicamp.

BARRO, R. (1990) “Government spending in a simple model of endogenous growth". Journal of Political Economy, v. 98, p. 103-125, Oct.

BASU, P. (2001) “Reserve ration, seigniorage and growth". Journal of Macroeconomics, Summer, v. 33, n. 3, p. 397-416.

BECSI, Z., WANG, P. (1997) “Financial development and growth". Economic Review: Federal Reserve Bank of Atlanta, 4th quarter.

CHARI, V. V., JONES, LARRY E., MANUELLI, RODOLFO E. (1995) “The growth effects of monetary policy. Federal Reserve Bank of Minneapolis”. Quartely Review, v. 19, n. 4, p. 18-32.

CHIANG, A. C. (1992) Dynanmic Optimization. Nova York: Mcgrow-Hill.

CYSNE, R. P. (1994) “Imposto inflacionário e transferências inflacionárias no Brasil”. Revista de Economia Política, 14, n. 3, jul.-set.

DIAS, M. H. A. (1997) “An interpretation of Cagan's model: Evidence for the welfare costs of inflation in Brazil”. In: XXV Encontro Nacional de Economia. Recife: Anpec (CD-ROM).

DICKEY, D. A., FULLER, W. A. (1979) "Distribution of the estimators for autorregressive time series with a unit root". Journal of The American Statistical Association, v. 74, p. 427-431.

ENDERS, W. (1995) Applied Econometric Time Series. Nova York: Jonh Wiley and Sons, Inc.

ENGLE, R. F., HENDRY, D. F., RICHARD, J. F. (1983) “Exogeneity”. Econometrica, v. 51, p. 277 304. 
FUENTE, A., MARIN, J. M. (1996) “Innovation, bank monitoring, and endogenous financial development”. Journal of Monetary Economics, v. 38, p. 269-301.

GRANGER, C. W. J. (1969) "Investigatin causal relations by econometric models and crosssspectral methods". Econometrica.

GREENE, W. H. (1997) Econometric Analysis. 3. ed. New Jersey: Prentice Hall.

GOLDSMITH, R. (1969) Financial Structure and Development. New Haven e Londres: Yale University Press.

HASLAG, J. H. (1998) “Monetary Policy: Banking and growth”. Economic Inquiry, v. 36, n. 3, p. $489-500$.

IPEADATA - Indicadores Ipea. Disponível em: <http://www.Ipeadata.gov.br.htm $>$. Acesso em $25 / 9 / 2004$.

LEVINE, R., LOYAZA, N., BECK, T. (2000) "Financial intermediation and growth: causality and causes”. Journal of Monetary Economics, 46 (1): 31-77.

MACKINNON, J. G. (1991) “Critical values of cointegration test”. In: Engle, R. F., Granger, C. W. J. (orgs.). Long Run Economic Relationships: readings in cointegration. Nova York: Oxford University Press.

MARQUES JR., T. T., PORTO JR., S. S. (2004) "Desenvolvimento financeiro e crescimento econômico no Brasil - Uma avaliação econométrica”. XXIII Encontro da Anpec Sul. Maringá: Anpec Sul (CD-ROM).

MATOS, O. C. (2002) "Desenvolvimento do sistema financeiro e crescimento econômico no Brasil: evidências de causalidade”. Texto para discussão do Banco Central do Brasil, set.

MONTE, P. A., TÁVORA JR., J. L. (2000) "Fontes de financiamento do Nordeste e o produto interno bruto da região". Revista Econômica do Nordeste, 31 (n. especial), p. 676-695, nov. Trabalho apresentado no V Encontro Regional de Economia.

PAGANO, M. (1993) “Financial markets and growth”. European Economic Review, 37 (April): 613-22.

PHILLIPS, P. C. B., PERRON, P. (1987) “Testing for a unit root in times series Regression”. Biometrika, v. 75, p. 335-346.

REBELO, S. (1991) “Long-run policy analysis and long-run growth”. Journal of PoliticalEconomy, v. 99 , n. 3, p. $500-521$.

ROCHA, R. R., SALDANHA, F. (1995) "Fiscal and quasi-fiscal deficit, nominal and real: measured and policy issues". Revista Brasileira de Economia. Rio de Janeiro, v. 49 (3), p. 431465 , jul.-set.

ROUBINI, N., SALA-I-MARTIN, X. (1995) “A growth model of inflation, tax evasion and financial repression”. Journal of Monetary Economics, v. 35, p. 275-301.

SAID, S. E., DICKEY, D. A. (1984) “Testing for unit root in autoregressive - moving average models of unknown order". Biometrika, v. 71, p. 599-607.

SHAW, E. W. (1973) Financial Deepening in Economic Development. Nova York: Oxford University Press. 